\title{
AVALIAÇÃO QUALI-QUANTITATIVA DA ESPÉCIE Licania tomentosa (Benth.) Fritsch. NA ARBORIZAÇÃO VIÁRIA DE BONITO-MS
}

\author{
QUALI-QUANTITATIVE EVALUATION OF Licania tomentosa (Benth.) Fritsch. AT \\ STREET AFFORESTATION OF BONITO-MS
}

\author{
Kendra Zamproni ${ }^{1}$, Daniela Biondi ${ }^{2}$, Rogério Bobrowski ${ }^{3}$
}

\section{RESUMO}

A avaliação da arborização de ruas é fundamental para o planejamento e manutenção deste patrimônio de modo a maximizar os benefícios proporcionados pelas árvores nas cidades. O objetivo deste trabalho foi avaliar de forma quantitativa e qualitativa os indivíduos da espécie Licania tomentosa (Benth.) Fritsch. (oiti) na arborização viária do município de Bonito-MS. Foram contabilizadas todas as árvores da área urbanizada do município e para a avaliação qualitativa realizou-se um inventário por amostragem aleatória com parcelas lineares de $400 \mathrm{~m}$. Para a caracterização dos oitis foram obtidas as seguintes variáveis: CAP, altura total, altura de bifurcação, diâmetro de copa, condição física e sanitária, necessidade de tratamento e condição de raiz. Foram amostrados ao todo 589 indivíduos de oiti, distribuídos em 17 unidades amostrais. Analisando as distribuições diamétrica e hipsométrica verifica-se a predominância de indivíduos com pequena e média altura. A altura de bifurcação média foi de $0,84 \mathrm{~m}$. Mais de $60 \%$ dos indivíduos foram classificados como regulares, com condição física e vigor medianos. É aconselhável a suspensão de novos plantios desta espécie para o equilíbrio com a frequência das demais espécies, a fim de aumentar a diversidade e contribuir para a melhoria estética e ecológica da cidade.

Palavras-chave: Inventário; Diagnóstico; Planejamento; Oiti; Ecologia urbana.

\section{ABSTRACT}

The evaluation of street afforestation is essential for planning and maintenance of this patrimony in order to maximize the benefit provided by trees in the street. This study aimed to evaluated quantitatively and qualitatively the individuals of the species Licania tomentosa (Benth.) Fritsch. (oiti) in the street afforestation of Bonito-MS. There were counted all trees in the municipality's urbanized area and for the qualitative analysis a random sampling inventory was performed with linear parcels of $400 \mathrm{~m}$. For the characterization of $L$. tomentosa individuals there were obtained the following variables: $\mathrm{CBH}$, total height, bifurcation height, canopy diameter, physical and phytosanitary condition, need of treatment and root condition. A total of 589 individuals of oiti were characterized, distributed in 17 parcels. Analyzing the diametric and hypsometric distributions, it was possible to verify the predominance of individuals with small and medium height. The average of bifurcation height founded was $0.84 \mathrm{~m}$. More than $60 \%$ of individual were classified as regulars, with median physical condition and vitality. It is advisable the suspension of new planting of this species for the balance with the frequency of other species, in order to increase diversity and contribute for the aesthetic and ecological improvement of the city.

Keywords: Inventory, Diagnostic, Planning. Oiti, Urban ecology.

\footnotetext{
Recebido em 26.04.2016 e aceito em 17.06.2016

1 Engenheira Florestal, Mestranda do Programa de pós-graduação em Engenharia Florestal da Universidade Federal do Paraná. Curitiba/PR. Email: kendra.zam@gmail.com

2 Engenheira Florestal, Prof ${ }^{\mathrm{a}} \mathrm{Dr}^{\mathrm{a}}$ da Universidade Federal do Paraná. Curitiba/PR. Email: dbiondi@ufpr.br

3 Engenheiro Florestal, Prof $^{\circ}$ Drํo da Universidade Estadual do Centro-Oeste. Irati/PR. Email: bobrowski_roger@yahoo.com.br
} 


\section{INTRODUÇÃO}

A arborização de ruas é um elemento essencial para a recuperação do equilíbrio ambiental do meio urbano. Sua importância reside na promoção de uma melhor qualidade de vida para a população, amenizando os efeitos artificiais desse ambiente.

De acordo com Biondi e Althaus (2005), a arborização de ruas, além de ser um serviço público, é um patrimônio que deve ser conhecido e conservado para as futuras gerações, devido às suas inúmeras contribuições. As autoras elencam alguns benefícios exercidos pela arborização tais como: beleza paisagística, equilíbrio do solo, regulação do microclima, promoção de abrigo à fauna, diminuição da velocidade do vento e poluição sonora, redução da temperatura do ar por meio do aumento da umidade relativa e produção de oxigênio, sensação de bem-estar à população, agindo na saúde física e mental.

A falta de diretrizes e normas para a arborização viária permite que iniciativas particulares desprovidas de conhecimento técnico tomem espaço por meio de plantios irregulares, acarretando na redução dos benefícios proporcionados pelas árvores e muitas trazendo vezes transtornos para a população (ALMEIDA; RONDON NETO, 2010). Dessa forma, conhecer a condição das árvores no ecossistema urbano é fundamental para um manejo adequado, visando uma maior eficiência das múltiplas contribuições trazidas por estas ao ambiente.

Nesse sentido, Bobrowski (2011) afirma que prefeituras e instituições de pesquisa têm realizado inventários florestais para verificar a qualidade, compreender o comportamento e detectar prejuízos e problemas advindos da arborização de uma cidade.

Uma das espécies frequentemente utilizada para compor a arborização de ruas nas cidades de regiões quentes do Brasil é Licania tomentosa (Benth.) Fritsch., da família Chrysobalanaceae, popularmente conhecida como oiti. Esta é uma árvore nativa, perenifólia e ocorre na floresta pluvial atlântica, desde Pernambuco até o norte do Espírito Santo e vale do Rio Doce em Minas Gerais. Sua altura varia de 6 a $15 \mathrm{~m}$, com tronco de 30 a $50 \mathrm{~cm}$ de diâmetro. Possui folhas simples, tomentosas em ambas as faces, de 7 a $14 \mathrm{~cm}$ de comprimento por 3 a $5 \mathrm{~cm}$ de largura. Floresce durante os meses de junho-agosto e seus frutos amadurecem em janeiro-março (LORENZI, 2008). Quando não são impostas restrições ao seu crescimento em altura por meio de podas, apresenta copa frondosa que proporciona sombra, característica bastante atrativa que justifica seu uso em larga escala na arborização urbana por quase todo o Brasil, especialmente a partir do estado de São Paulo em direção ao norte do país (FERREIRA; GASPAROTTO; LIMA, 2001). 
Dentro deste contexto, o objetivo deste trabalho foi avaliar de forma quantitativa e qualitativa os indivíduos da espécie Licania tomentosa presentes na arborização viária do município de Bonito-MS.

\section{MATERIAL E MÉTODOS}

Este estudo foi realizado no município de Bonito, localizado a sudoeste do estado do Mato Grosso do Sul, na região centro-oeste do Brasil (FIGURA 1), integrando a unidade geomorfológica denominada Serra da Bodoquena. O núcleo urbano do município $\left(21^{\circ} 07^{\prime} 16^{\prime \prime} \mathrm{S}\right.$ e 56²8'55" O) está a 250 km da capital do estado, Campo Grande (FEHLAUER et al., 2010).

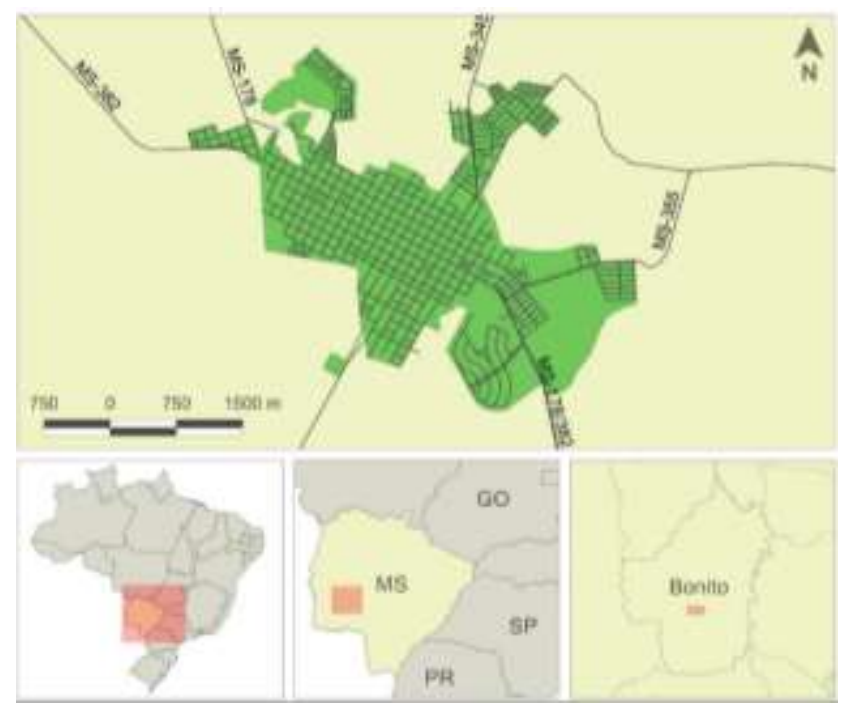

Figura 1. Localização geográfica de Bonito-MS, com destaque para a área urbana do município Figure 1. Geographic location of Bonito-MS, highlighting the urban area of the city

O clima da região é o Aw (tropical úmido), segundo a classificação de Köppen, caracterizado por estação seca acentuada entre os meses de abril e setembro com precipitações concentradas entre novembro e janeiro. A temperatura média anual é de $23,9^{\circ} \mathrm{C}$ e a precipitação varia entre 1200 e 1500 mm ao ano (SILVA et al., 2013).

De acordo com o IBGE (2014), o município de Bonito-MS possui uma área de $4.934,414 \mathrm{~km}^{2}$, sendo $3,483 \mathrm{~km}^{2}$ de área urbana, e uma população estimada de 20.825 habitantes. Mais de 16 mil pessoas (82,5\%) vivem na área urbana, enquanto $17,5 \%$ residem na área rural.

A coleta de dados ocorreu nos meses de junho e julho de 2015. Primeiramente, realizou-se uma estratificação da área urbanizada do município e esta foi dividida em área pavimentada e área não pavimentada. Esta divisão foi feita para que o inventário quali- 
quantitativo contemplasse a área da cidade com o mínimo de infraestrutura urbana implantada (asfalto).

O inventário quantitativo foi do tipo censo, sendo percorridas de carro todas as ruas da cidade inseridas na área pavimentada previamente delimitada, para contabilizar todos os indivíduos presentes na calçada. O inventário qualitativo foi realizado por amostragem aleatória, dentro da área estratificada, com parcelas lineares de 400 metros. A intensidade amostral foi calculada com um nível de confiança de $95 \%$, para um erro de $10 \%$.

Nas unidades amostrais sorteadas foram contabilizados quantitativamente todos os indivíduos arbóreos, herbáceos e palmeiras. Para a análise dendrométrica e da qualidade dos indivíduos de $L$. tomentosa, foram obtidas as seguintes variáveis (FIGURA 2): CAP (circunferência a altura do peito), altura total, altura de bifurcação, diâmetro de copa (em quatro raios), condição física e sanitária, necessidade de tratamento e condição de raiz.
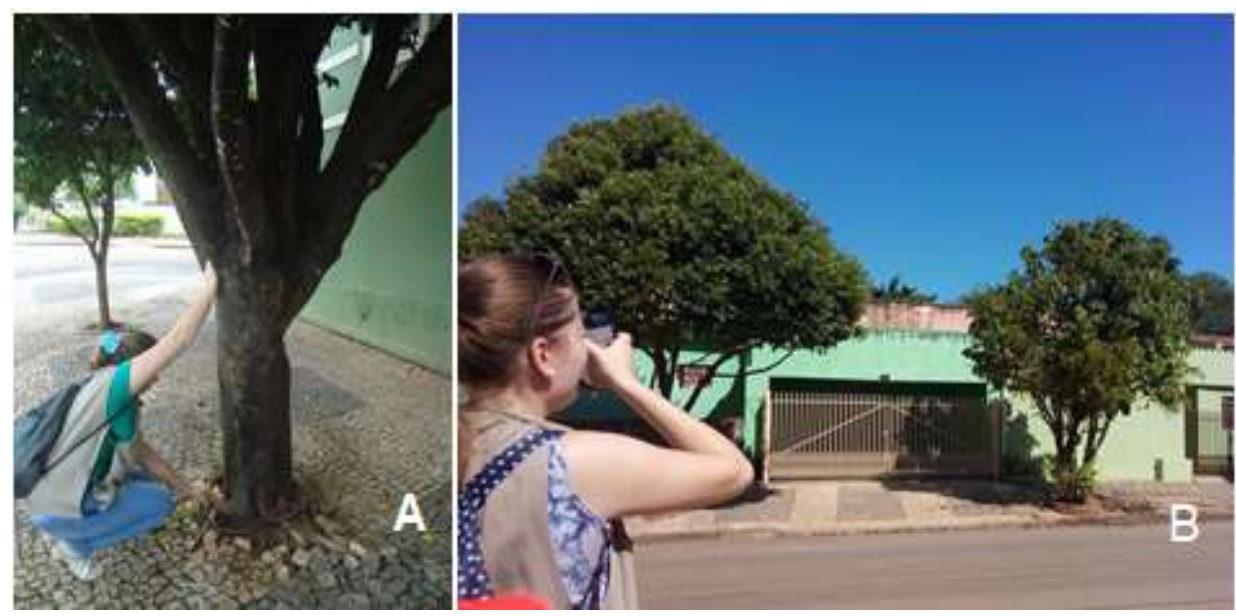

Figura 2. Caracterização dos indivíduos de L. tomentosa. A- Altura de bifurcação; B- altura total Figure 2. Characterization of $L$. tomentosa individuals. A- bifurcation height; B- total height

Para a avaliação da condição física e sanitária, as árvores foram classificadas, baseado em Milano (1984), em: 1) Árvore boa - que não apresenta sinais de pragas, doenças ou injúrias mecânicas, que apresenta a forma característica da espécie; 2) Árvore regular apresenta condição física e vigor medianos, que sofreu podas pesadas, mas que conseguiu se reestabelecer satisfatoriamente ou necessita reparo de danos físicos ou controle de pragas ou doenças; 3) Árvore ruim - apresenta muitos danos físicos, ataque de pragas ou doenças, tortuosidade; 4) Árvores muito ruins - apresentam danos físicos severos, que requerem muito trabalho de recuperação, morte iminente; 5) Árvore morta.

Os indivíduos amostrados foram diagnosticados de acordo com as seguintes necessidades de tratamento: 1) Poda de adequação/direcional - amenizar conflitos entre os galhos das árvores e equipamentos urbanos, principalmente a rede elétrica; 2) Poda de 
limpeza - retirada de galhos finos, secos e/ou senis afim de evitar quedas destes materiais; 3) Poda de formação/levamentamento de copa - direcionar o desenvolvimento da copa em árvores jovens e livrar o tronco de ramificações que dificultem o trânsito de pedestres na calçada; 4) Controle de pragas e/ou doenças e 5) Remoção. As árvores que devem ser retiradas são aquelas mortas, atacadas por cupins, com rachadura no fuste e/ou estão inseridas em lugares inadequados, causando transtornos e oferecendo riscos para a população.

O sistema radicular foi avaliado em três categorias: 1) Profundo, sem danos à calçada; 2) Pouco superficial, causando pequenos danos e superficial, 3) Superficial, causando danos à calçada.

Os dados obtidos com as medições foram transformados em planilhas no Microsoft Office Excel 2013, para posteriormente serem analisados em forma de gráficos e tabelas.

\section{RESULTADOS E DISCUSSÃO}

Contabilizou-se 947 indivíduos arbóreos, herbáceos e palmeiras em 17 unidades amostais, sendo 589 árvores da espécie L. tomentosa, que representam $63,27 \%$ da arborização viária de Bonito-MS. Foram encontradas 20 mudas de oiti (3,39\%), não sendo estas avaliadas qualitativamente. A frequência de L. tomentosa excede o proposto por Grey e Deneke (1978), que recomendam uma frequência entre 10 e 15\% em zonas urbanas de uma mesma espécie para evitar que a arborização de ruas de uma cidade seja dizimada por um surto de pragas e doenças.

A Tabela 1 apresenta a relação das unidades amostrais inventariadas com as respectivas quantidades de indivíduos (árvores, arbustos e palmeiras) e oitis encontrados, bem como a porcentagem de oitis por amostra.

Quando analisada a proporção de oitis em cada amostra, percebe-se que em nenhuma delas a frequência recomendada é atendida, sendo que em duas delas (amostras 82 e 28), a frequência de oitis atinge aproximadamente $90 \%$ do total, muito além do ideal. Stranghetti e Silva (2010) afirmam que a diversidade da vegetação é de grande importância para a ampliação, fixação e manutenção do equilíbrio ecológico no meio urbano. Entretanto, a adaptabilidade das espécies às condições do ambiente urbano é que deve ser um fator de importância no planejamento da arborização da cidade (RAUPP; CUMMING; RAUPP, 2006). 
Tabela 1. Relação das amostras inventariadas com os respectivos totais de indivíduos encontrados e árvores de oiti e porcentagem desta espécie

Table 1. Relation of inventoried samples with respective total individuals founded, L. tomentosa trees and percentage of this species

\begin{tabular}{|c|c|c|c|}
\hline AMOSTRA & $\begin{array}{l}\text { TOTAL DE } \\
\text { INDIVÍDUOS }\end{array}$ & $\begin{array}{l}\text { TOTAL DE } \\
\text { OITIS }\end{array}$ & (\%) OITIS \\
\hline 6 & 62 & 40 & 64,5 \\
\hline 7 & 62 & 31 & 50,0 \\
\hline 71 & 53 & 39 & 73,6 \\
\hline 68 & 42 & 14 & 33,3 \\
\hline 1 & 63 & 47 & 74,6 \\
\hline 103 & 80 & 43 & 53,8 \\
\hline 126 & 62 & 32 & 51,6 \\
\hline 19 & 52 & 23 & 44,2 \\
\hline 44 & 48 & 33 & 68,8 \\
\hline 82 & 48 & 43 & 89,6 \\
\hline 28 & 54 & 49 & 90,7 \\
\hline 48 & 44 & 24 & 54,5 \\
\hline 79 & 55 & 31 & 56,4 \\
\hline 112 & 46 & 22 & 47,8 \\
\hline 46 & 70 & 48 & 68,6 \\
\hline 4 & 44 & 16 & 36,4 \\
\hline 93 & 62 & 34 & 54,8 \\
\hline TOTAL & 947 & 589 & \\
\hline
\end{tabular}

A predominância desta espécie também foi verificada na arborização de ruas de outras cidades como: Goiandira-GO (PIRES et al., 2007), Assis-SP (ROSSATO; TSUBOY; FREI, 2008), Uchôa-SP (STRANGHETTI; SILVA, 2010), Matupá-MT e Colíder-MT (ALMEIDA; RONDON NETO, 2010), São João Evangelista-MG (BRANDÃO et al., 2011), Jerônimo Monteiro-ES (SILVA; CARDOSO; RAPHAEL, 2012), Cajuri-MG (SILVA; GONÇALVES, 2012) e Israelândia-GO (LARA; ALVES; CARNEIRO, 2014). Isto pode ser um reflexo da adaptabilidade da espécie a condições adversas do ecossistema urbano, crescendo e desenvolvendo de forma satisfatória.

A preferência por esta espécie na composição da arborização viária pode ser justificada por sua copa densa e perenifólia, que proporciona excelente sombreamento e por ter um sistema radicular profundo. Além disso, adapta-se a regiões de clima quente, como o norte do país e regiões litorâneas (LORENZI, 2008).

Entretanto, Ferreira, Gasparotto e Lima (2001) alertam que o plantio em larga escala de L. tomentosa deve ser evitado em função do aparecimento de ferrugem causada por Phakopsora tomentosae, que ocasiona a morte da árvore, conforme encontrado pelos autores em Manaus-AM. Dessa forma, a homogeneidade da arborização em Bonito-MS é preocupante, pois os indivíduos de oiti estão susceptíveis ao ataque de fitopatógenos que podem acarretar 
na morte das árvores e consequentemente um déficit expressivo na quantidade de árvores na cidade. Apesar disso, Raupp, Cumming e Raupp (2006) afirmam que baixas proporções de composição para algumas espécies não consegue extinguir os problemas com pragas e doenças porque alguns patógenos podem atacar mais de uma espécie. Sendo assim, ao compor a arborização viária é necessário considerar o equilíbrio de frequência entre espécies conjuntamente com a adaptabilidade das mesmas.

Com relação à caracterização dendrométrica, as figuras 3 e 4 apresentam, respectivamente, as distribuições diamétrica e hipsométrica das árvores de $L$. tomentosa inventariadas.

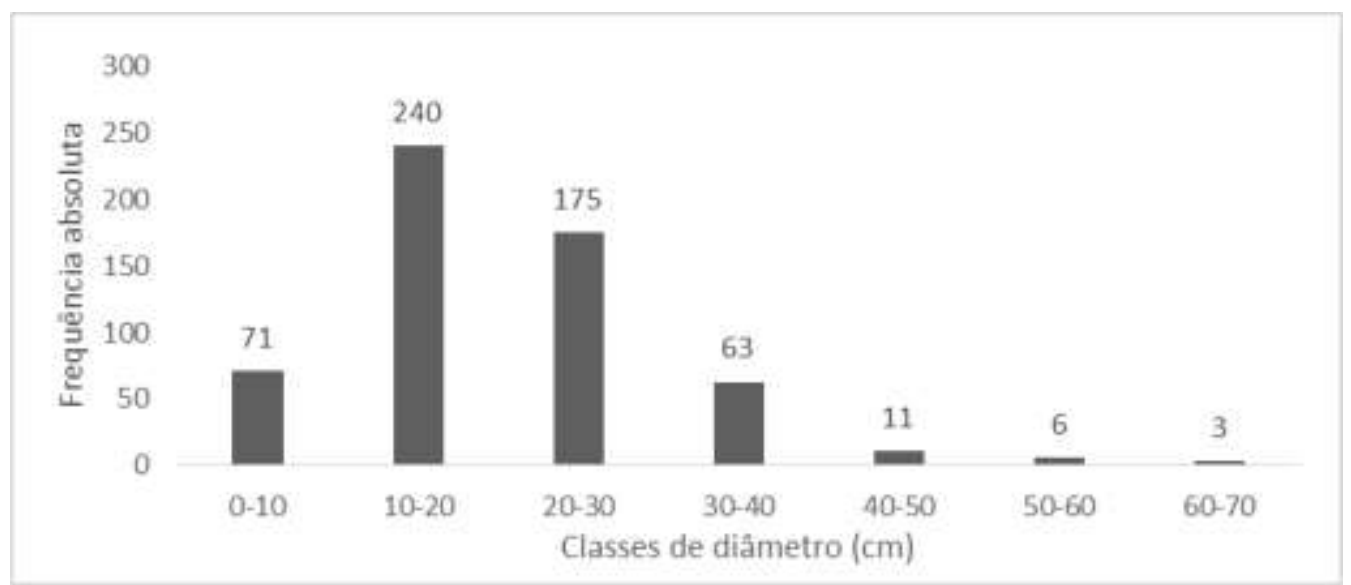

Figura 3. Distribuição diamétrica dos indivíduos de L. tomentosa inventariados

Figure 3. Diametric distribution of L. tomentosa individuals inventoried

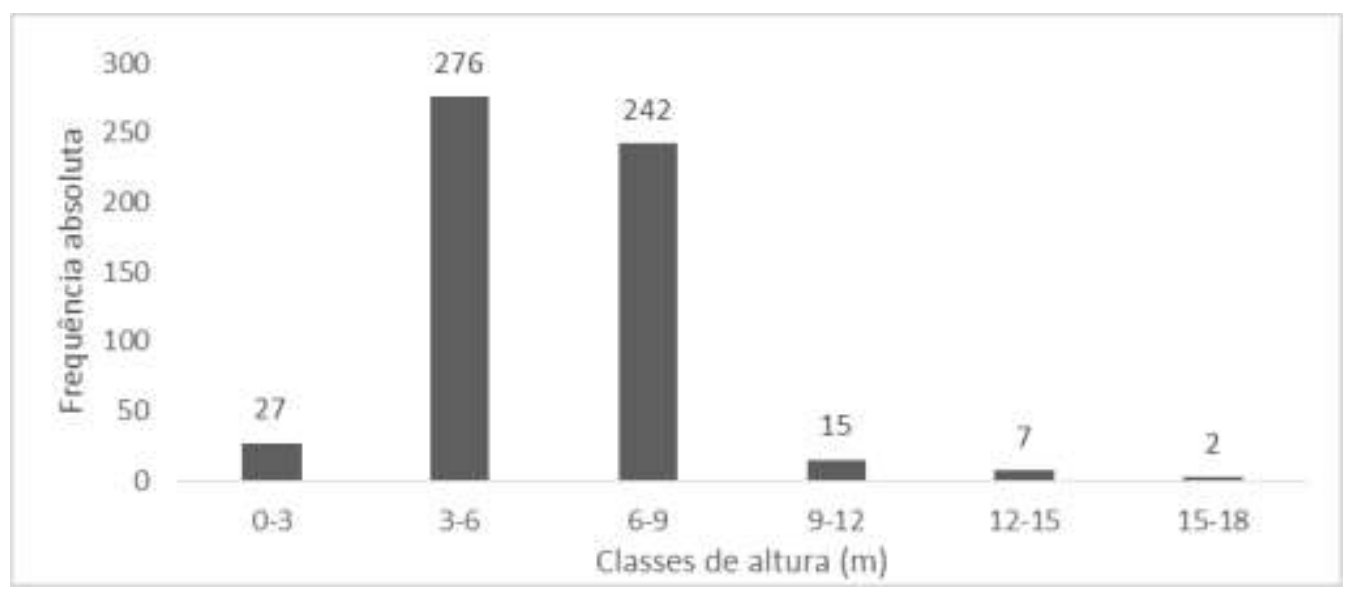

Figura 4. Distribuição hipsométrica dos indivíduos de L. tomentosa inventariados Figure 4. Hypsometric distribution of $L$. tomentosa individuals inventoried

$\mathrm{Na}$ distribuição das classes diamétricas encontrou-se maior frequência de indivíduos na classe de 10 a $20 \mathrm{~cm}$, caracterizados como indivíduos de pequeno e médio porte. O mesmo foi verificado com relação à altura, já que a maioria das árvores se enquadrou nas classes de 3 a 9 metros. Infere-se, portanto, que a maioria dos indivíduos ainda são jovens (não atingiram 
sua maturidade) e não atingiram suas dimensões máximas, já que de acordo com a literatura, a espécie $L$. tomentosa possui altura entre 6 a $15 \mathrm{~m}$, com tronco de 30 a $50 \mathrm{~cm}$ de diâmetro (LORENZI, 2008). Dessa maneira, é importante considerar medidas de manutenção e manejo dessas árvores, para que não haja danos e conflitos com os equipamentos urbanos no futuro, bem como perdas dos potenciais benefícios que essas possam oferecer à cidade.

Cabe ressaltar, porém, que a distribuição em classes de altura da arborização sofre influência direta do tipo de poda realizada, principalmente por podas drásticas, em que toda ou a maioria da copa foi retirada, e de rebaixamento de copa (comuns em Bonito-MS, conforme observado nesse estudo), que alteram as características naturais de altura e arquitetura de copa das espécies (BOBROWSKI, 2011).

Essa mesma condição de predominância de indivíduos da espécie L. tomentosa nas primeiras classes de altura devido às podas de rebaixamento de copa também foi constatado por Silva, Cardoso e Raphael (2012), na cidade de Jerônimo Monteiro-ES,

Em relação à copa, a figura 5 mostra a distribuição dos indivíduos amostrados em classes de área de copa.

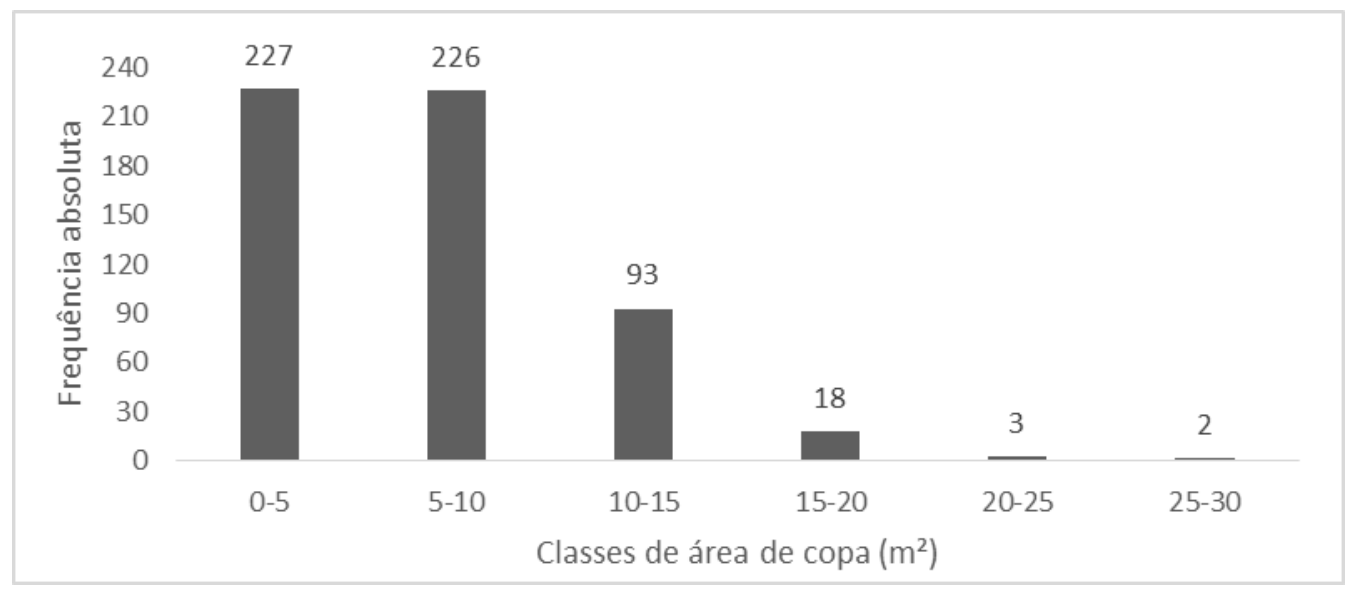

Figura 5. Distribuição em classes de altura dos indivíduos de L. tomentosa inventariados

Figure 5. Distribution into canopy area classes of the L. tomentosa individual inventoried

Verifica-se a predominância de árvores com áreas de copas pequenas $\left(0-10 \mathrm{~m}^{2}\right)$, reflexo da arborização jovem e do tipo de poda inadequado frequentemente realizado na cidade (poda drástica e de rebaixamento de copa). Esta característica não é interessante em uma cidade como Bonito-MS, a qual apresenta temperaturas elevadas, pois acarreta em menor sombreamento e menor evapotranspiração. A copa das árvores é a principal fonte de benefícios ambientais e estéticos para os centros urbanos e como consequência das podas malfeitas tem-se a perda destes benefícios (BOBROWSKI; BIONDI, 2012). 
A altura de bifurcação média encontrada nos indivíduos de $L$. tomentosa foi de $0,84 \mathrm{~m}$, sendo que $1,94 \%$ possui bifurcação rente ao solo. Recomenda-se que a altura da primeira bifurcação não seja menor que 1,8 metros, pois representa um problema com relação ao trânsito livre entre os pedestres, principalmente para aqueles com mobilidade reduzida (LIMA NETO et al., 2010).

A Tabela 2 apresenta a distribuição dos indivíduos amostrados de acordo com a classificação de condição física e fitossanitária.

Tabela 2. Classificação da condição física e fitossanitária das árvores inventariadas, com respectivas frequências absoluta e relativa

Table 2. Classification of the physical and phytosanitary condition of the trees inventories with respective relative and absolute frequencies

\begin{tabular}{ccc}
\hline Condição & FA & FR (\%) \\
\hline Árvore boa & 152 & 26,71 \\
Árvore regular & 345 & 60,63 \\
Árvore ruim & 67 & 11,78 \\
Árvore muito ruim & 5 & 0,88 \\
\hline
\end{tabular}

A maioria das árvores foi considerada regular, com condição fisíca e vigor medianos, demonstrando recuperação satisfatória após sofrerem danos. Diversos indivíduos apresentaram danos no fuste e nos galhos decorrentes de podas mal executadas, acidentes com veículos ou vandalismo. Alguns destes danos são severos, comprometendo a estabilidade da árvore e aumentando a susteptibilidade à ataque de patógenos (FIGURA 6).
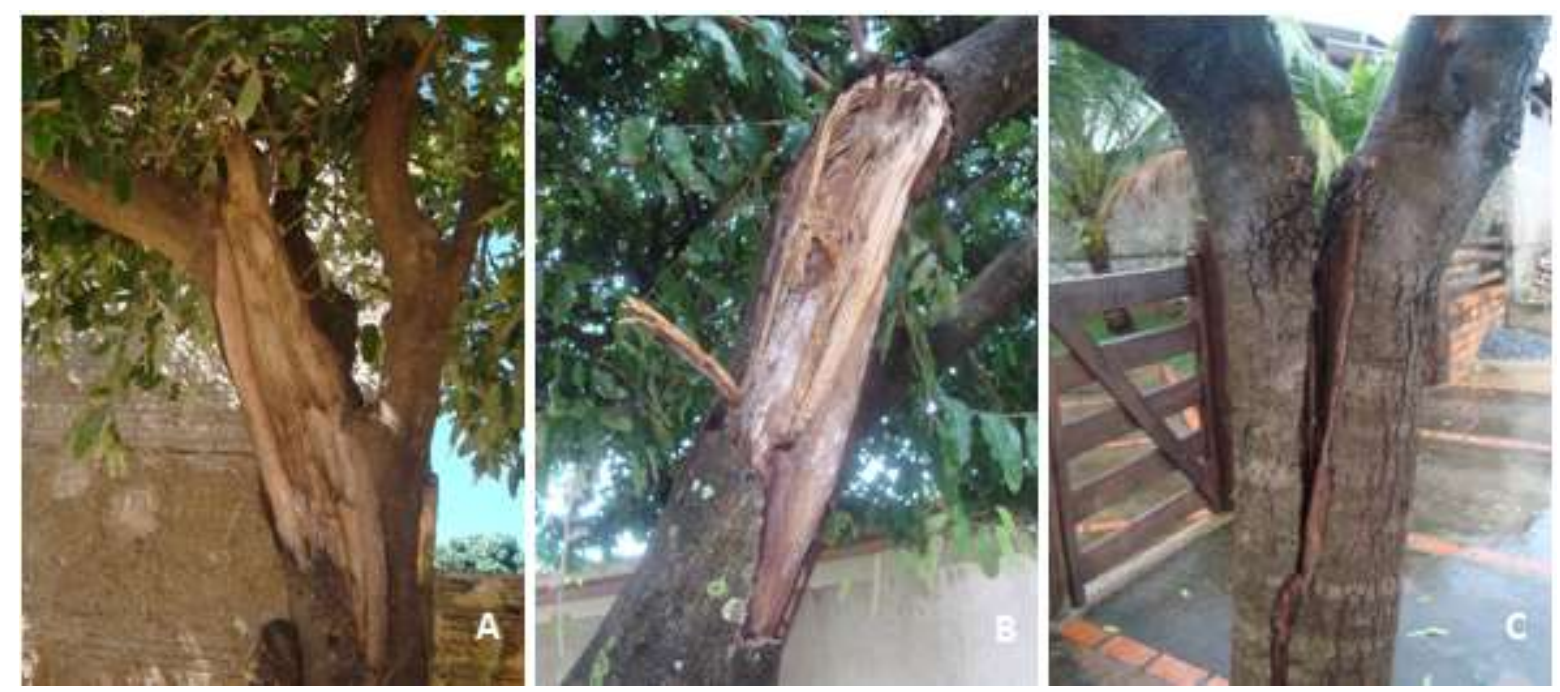

Figura 6. Danos físicos e defeitos estruturais encontrados em oitis na cidade de Bonito-MS. A, B galhos quebrados com podridão associada e cancro pós lesão. $C$ - Rachadura em fissura de galhos com bifurcação em "V"

Figure 6. Physical damages and structural defects founded in L.tomentosa trees in Bonito-MS. A,B broken branches with associated rot and canker post injury. $\mathrm{C}$ - splitting in fissure of branches in "V" bifurcation 
De acordo com Zem e Biondi (2014), mesmo com os inúmeros benefícios proporcionados pelas árvores de ruas, estas continuam sendo danificadas devido à falta de planejamento quanto ao local onde serão plantadas e falta de envolvimento da população, que deveria ser uma prioridade em todas as fases da arborização de uma cidade.

Com relação aos aspectos fitossanitários foram diagnosticadas nove árvores com presença de percevejo, oito árvores com presença de formiga, uma árvore com ataque de cupim e uma árvore com presença de fungo, indicando boa resistência da espécie $L$. tomentosa a ataque de pragas e doenças, mesmo o plantio da espécie sendo caracterizado como uma monocultura na cidade, havendo condições favoráveis para a proliferação de pragas e doenças.

A Tabela 3 apresenta as necessidades de tratamento indicadas para os indivíduos amostrados, sendo que uma árvore pode apresentar mais de uma recomendação (FIGURA 7).

Tabela 3. Necessidades de tratamento indicadas para as árvores inventariadas com respectivas frequências absoluta e relativa

Table 3. Treatment needs indicated for the inventoried trees with respective absolute and relative frequencies

\begin{tabular}{ccc}
\hline Necessidade de tratamento & FA & FR (\%) \\
\hline Poda de adequação/direcional & 335 & 58,88 \\
Poda de limpeza & 232 & 40,77 \\
Poda de formação/levantamento & 113 & 19,86 \\
Controle de praga e/ou doença & 17 & 2,99 \\
Remoção & 8 & 1,41 \\
\hline
\end{tabular}

De acordo com Biondi e Althaus (2005), a poda é uma prática de manutenção muito importante nas árvores de rua, devendo ser executada por pessoas habilitadas de modo a não afetar a saúde e a estética das árvores.

Mais de $58 \%$ das árvores apresentam algum tipo de conflito ou então poderão apresentar conflitos com componentes urbanos (fiação, construções) e, portanto, recomendase a poda de adequação/direcional. A necessidade de podas de levantamento de copa está intimamente relacionada à baixa altura de bifurcação encontrada nas árvores, problema proveniente do plantio de mudas com características inadequadas para a implementação no meio urbano. Essas características poderiam ser melhoradas com o manejo adequado das mudas ainda no viveiro. 

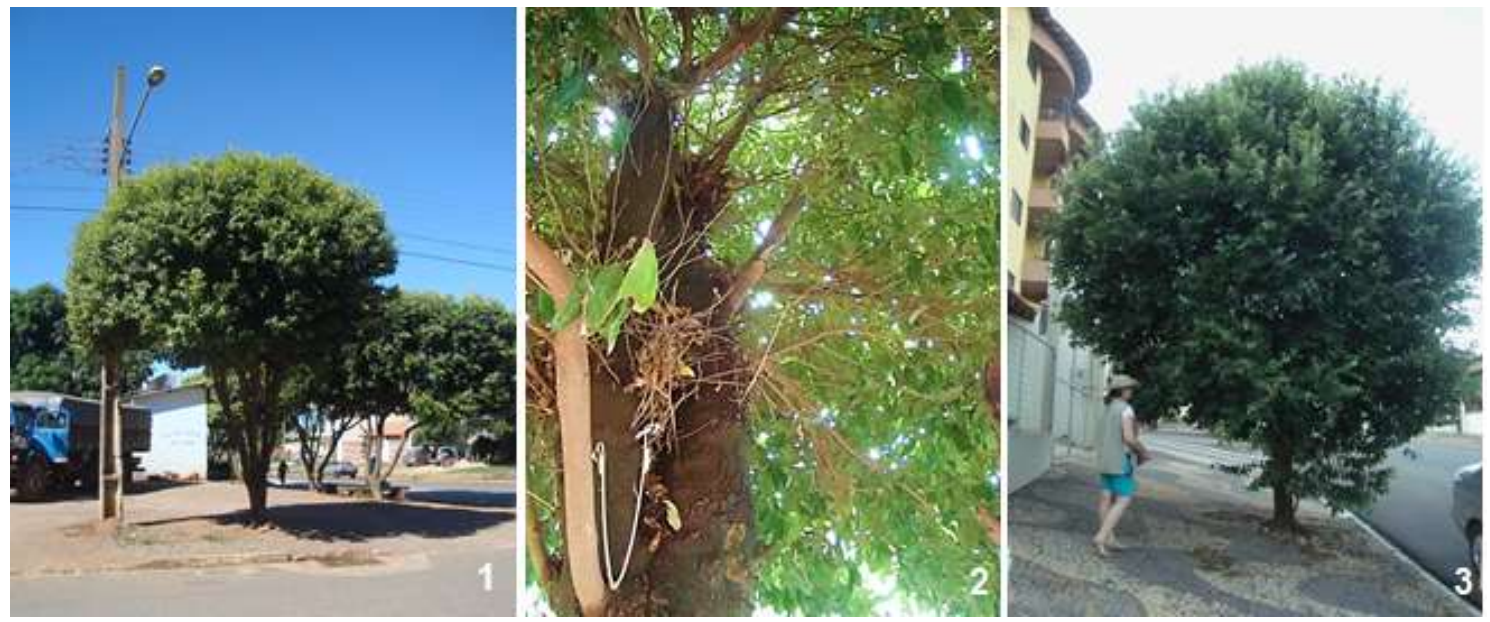

Figura 7. Necessidade de tratamento das árvores de Bonito-MS: (1) poda de adequação/direcional, (2) poda de limpeza, (3) poda de formação/levantamento da copa.

Figure 7. Treatment needs in the trees of Bonito-MS: 1- adequacy/directional pruning, 2- cleaning pruning, 3- formation/canopy lifting pruning.

Com relação ao sistema radicular, a Tabela 4 mostra a classificação dos indivíduos inventariados.

Tabela 4. Classificação do sistema radicular das espécies inventariadas, com respectivas frequências absoluta e relativa

Table 4. Treatment needs in the trees of Bonito-MS: 1- adequacy/directional pruning, 2- cleaning pruning, 3- formation/canopy lifting pruning

\begin{tabular}{ccc}
\hline Raiz & FA & FR (\%) \\
\hline Profunda & 414 & 72,76 \\
Pouco superficial & 115 & 20,21 \\
Superficial & 40 & 7,03 \\
\hline
\end{tabular}

Não foram verificados problemas significativos de incompatibilidade da raiz com o calçamento, já que mais de $72 \%$ das árvores apresentou sistema radicular profundo, como também descrito em literatura sobre a espécie. Em estudo sobre a arborização viária do município de São João Evangelista-MG, Brandão et al. (2011), diagnosticaram apenas 0,6\% dos indivíduos de L. tomentosa com raízes superficiais causando danos ao calçamento.

Esta característica está também relacionada à manutenção dos canteiros permeáveis, que interferem diretamente no desenvolvimento das árvores. Bobrowski, Biondi e Baggenstoss (2009) ressaltam a importância das áreas permeáveis no entorno das árvores de rua numa extensão tão maior quanto o possível, para efetivamente proporcionar o crescimento destas e evitar gastos com substituições de árvores em consequência de local inapropriado ao desenvolvimento e danos acarretados em função disto. De acordo com Lima Neto et al. (2010), árvores com raízes que se desenvolvem acima do solo, danificando as calçadas, são um 
impedimento para a acessibilidade dos pedestres, em especial dos deficientes e com mobilidade reduzida.

Em seis indivíduos foi constatado enovelamento/retorcimento da raiz (FIGURA 8), que pode causar o estrangulamento da base do tronco e consequentemente a queda da árvore. Isto provém da produção de mudas de má qualidade no viveiro ou de práticas inadequadas de plantio.
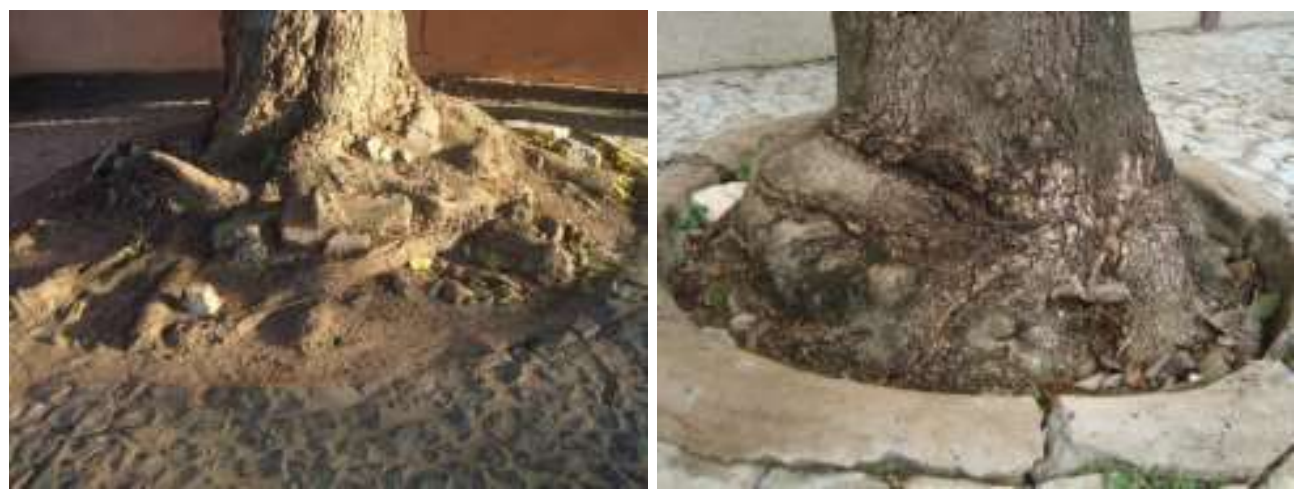

Figura 8. Raiz enovelada em indivíduos adultos de oiti

Figure 8. Coiled root in adult individuals of L.tomentosa

\section{CONCLUSÕES}

A partir dos resultados obtidos verifica-se uma homogeneização da arborização viária do município de Bonito-MS com a predominância da espécie L. tomentosa. Assim, sugere-se a adoção de medidas de introdução de novas espécies a fim de diminuir a frequência de oitis, bem como a suspensão de novos plantios desta espécie, de modo a contribuir para a melhoria estética e ecológica da cidade e evitar a perda do patrimônio arbóreo do município em caso de um surto de praga ou doença.

No que diz respeito à qualidade das árvores, constata-se pela avaliação dendrométrica que grande parte dos indivíduos de L. tomentosa presentes na arborização de Bonito- MS ainda são jovens. A altura de bifurcação encontrada é problemática, pois a grande maioria está abaixo dos padrões técnicos que recomendam altura mínima de 1,8m. Sugere-se a adoção de podas de levantamento de copa para as árvores já implantadas nas ruas.

Para os novos plantios, sugere-se estabelecer um padrão de qualidade das mudas referente a altura e diâmetro. Não foram detectados problemas significativos com relação a pragas e doenças, porém foram observados vários danos físicos e até mesmo podas drásticas. Dessa maneira, recomenda-se a adoção de programas de educação ambiental no município para maior conscientização da população a respeito da importância das árvores no meio urbano. 


\section{AGRADECIMENTOS}

À Fundação Neotrópica do Brasil e à Prefeitura Municipal de Bonito, pelo apoio financeiro e oportunidade de realização desta pequisa.

\section{REFERÊNCIAS}

ALMEIDA, D. N.; RONDON NETO, R. M. Análise da arborização urbana de duas cidades da região norte do estado de Mato Grosso. Revista Árvore, Viçosa-, v. 34, n. 5, p. 899-906, 2010.

BIONDI, D.; ALTHAUS, M. Árvores de rua de Curitiba: cultivo e manejo. Curitiba: FUPEF, 2005. 175p.

BOBROWSKI, R. Inventário florestal contínuo e dinâmica da arborização de ruas. In: BIONDI, D.; LIMA NETO, E. M. de (Org.) Pesquisas em arborização de ruas. Curitiba, 2011. p. 91110.

BOBROWSKI, R.; BIONDI, D. Distribuição e dinâmica da área de copa na arborização de ruas de Curitiba, Paraná, Brasil, no período de 1984-2010. Revista Árvore, Viçosa-, v. 36, n. 4, p. 625-635, 2012.

BOBROWSKI, R.; BIONDI, D; BAGGENSTOSS, D. Composição de canteiros na arborização de ruas de Curitiba (PR). Revista da Sociedade Brasileira de Arborização Urbana, Piracicaba, v.1, n.1, p. 44-61, 2009.

BRANDÃO; I. M.; GOMES, L. B.; SILVA, N. C. A. R.; FERRARO, A. C.; SILVA, A. G.; GONÇALVES, F. G. Análise quali-quantitativa da arborização urbana do município de São João Evangelista--, Revista da Sociedade Brasileira de Arborização Urbana, Piracicaba: v. 6, n. 4, p. 158-174, 2011.

FEHLAUER, T. J.; RODRIGUER-OTUBO, B. M.; SANDRINI, M.; DESTRO, D. Caracterização da produção de genótipos de banana introduzidos na região de Bonito -. Revista Brasileira de Fruticultura, v. 32, p. 938-943, 2010.

FERREIRA, F. A.; GASPAROTTO, L.; LIMA, M. I. P. M. Uma ferrugem, causada por Phakopsora tomentosae em oiti, em Manaus. Fitopatologia Brasileira, Brasília, v. 26, n. 2, p. $206-208,2001$.

GREY, G. W.; DENEKE, F. J. Urban forestry. New York: John Wiley, 1978.

INSTITUTO BRASILEIRO DE GEOGRAFIA E ESTATÍTICA (IBGE). Informações municipais - 2014. Disponível em: <

http://www.cidades.ibge.gov.br/xtras/perfil.php?lang=\&codmun=500220\&search=mato-grossodo-sul|bonito|infograficos:-informacoes-completas>. Acesso em: 29 ago. 2015.

LARA, J. S.; ALVES, E. D. L.; CARNEIRO, F. M. Diagnóstico da composição arbórea da cidade de Israelândia-GO, Brasil. Revista da Sociedade Brasileira de Arborização Urbana, Piracicaba , v. 9, n. 2, p. 134-147, 2014. 
LIMA NETO, E. M. de.; BARDELLI-DA-SILVA, M. Y.; SILVA, A. R.; BIONDI, D. Arborização de ruas e acessibilidade no bairro centro de Curitiba-PR. Revista Sociedade Brasileira de Arborização Urbana, Piracicaba-, v. 5, n. 4, p. 40-56, 2010.

LORENZI, H. Árvores brasileiras: manual de identificação e cultivo de plantas arbóreas nativas do Brasil. 5.ed. Nova Odessa: Editora Plantarum, 2008. 384p.

MILANO, M.S. Avaliação e análise da arborização de ruas de Curitiba-PR. $130 f$.

Dissertação (Mestrado em Ciências Florestais) - Universidade Federal do Paraná, Curitiba, 1984.

PIRES, N. A. M.T.; MELO, M. S.; OLIVEIRA, D. E.; XAVIER-SANTOS, S. Diagnóstico da Arborização Urbana do Município de Goiandira, Goiás. Revista Brasileira de Biociências, Porto Alegre, v. 5, supl. 1, p. 537-539, jul. 2007.

RAUPP, M. J., CUMMING, A. B., RAUPP, E. C. Street tree diversity in eastern north America and its potential for tree loss to exotic borers. Arboriculture \& Urban Forestry, v. 32, n. 6, p. 297-304, 2006.

ROSSATO, D. R.; TSUBOY, M. S. F.; FREI, F. Arborização urbana na cidade de Assis-SP: uma abordagem quantitativa. Revista da Sociedade Brasileira de Arborização Urbana, Piracicaba -, v. 3, n. 3, p. 1-16. 2008.

SILVA, A. G.; CARDOSO, A. L.; RAPHAEL, M. Diagnóstico quali-quantitativo da arborização viária da cidade de Jerônimo Monteiro-ES. Enciclopédia Biosfera, Goiânia-, v. 8, n.14, p. 1179, 2012.

SILVA, A. G.; GONÇALVES, W. Inventário e diagnóstico da arborização da cidade de CajuriMG. Enciclopédia Biosfera, Goiânia-, v. 8, n.15, p. 1102, 2012.

SILVA, M. B.; ANJOS, L. H. C.; PEREIRA, M. G.; SCHIAVO, J. A.; COOPER, M.; CAVASSANI, R. S. Gênese e classificação dos solos de uma topossequência em área de carste na Serra da Bodoquena, MS. Revista Brasileira de Ciência do Solo, Viçosa-, v. 31, n. 6, 2013.

STRANGHETTI, V.; SILVA, Z. A. V. Diagnóstico da arborização das vias públicas do município de Uchôa - SP. Revista da Sociedade Brasileira de Arborização Urbana, Piracicaba--, v. 5, n. 2, p.124-138, 2010.

ZEM, L. M.; BIONDI, D. Análise da percepção da população em relação ao vandalismo na arborização viária de Curitiba -PR. Revista da Sociedade Brasileira de Arborização Urbana, Piracicaba-, v. 9, n. 3, p. 86-107, 2014. 